\title{
Loess plateau ecological agricultural development thinking -take an example of Qingyang city, Gansu province
}

\author{
Xue fengli ${ }^{1}$ \\ ${ }^{1}$ Longdong University,Qingyang,Gansu province, 745000) \\ ${ }^{a}$ Email: gww2008ok@126.com
}

Key words: Loess Plateau; Ecological Agriculture; Development Thinking

\begin{abstract}
. to strengthen the environmental protection and ecology of longdong loess plateau governance, taking the Qingyang city located in the loess hilly-gully region as an example, using the way of empirical analysis, and using many countries experience, the paper studies the ecological agriculture development model and development environment, and puts forward specific way to accelerate the development of ecological agriculture, the aim is to realize the agricultural sustainable development in the loess plateau.
\end{abstract}

\section{Introduction}

With the continuous improvement of living standards, the concept of sustainable development has been growing, people gradually pay attention to the protection of natural environment, the development of ecological agriculture has become a general trend. Ecological agriculture in our country is to agricultural production and rural economic development, efficient utilization of resources, protecting environment, and integration of new agriculture system, it is a strategic decision of agricultural development, is also a necessary choice for the sustainable development of rural areas. Loess plateau is a typical farming-pastoral region in our country and fragile ecological environment area, is also the heart of dry land agriculture in our country, the region contains the rich resources of arable land and sunlight, deep loose loess and widely distributed on the unique ecological environment, with intensive production and the potential advantages of scale operation, but the water resources and environmental problems have been bothering the disadvantage factor in the development of agriculture, the agricultural system productivity level is low in the region. Qingyang is a typical representative of the loess plateau area, agriculture is the leading industry of Qingyang, under pressure from resources and environment, the sustainable development will inevitably face severe challenges. In Qingyang city as an example, this article adopts the empirical analysis method, analyze the current situation of the development of ecological agriculture in the region, using the experience of the development of relevant countries, put forward the development idea of Qingyang ecological agriculture, to improve the efficiency of the loess plateau ecological agriculture provide beneficial reference.

\section{Current Situation of the Development of Ecological Agriculture in the Study Area}

Profile in the study area .Locates in the eastern part of Gansu province, and in the southwestern Ordos basin, Qingyang city is the loess plateau gully region, is also the main component of longdong loess plateau. the terrain is of high middle and low around the basin, the climate type is temperate semi-arid continental monsoon , the rainfall is of more than south north, less total land area of 27117.27 square kilometers, the total population was 2.2235 million, including the rural population accounted for 68.5\%. The city covers Xifeng, Qingyang, Huachi, Heshui,Zhengyuan, Ningxian,Zhengning county, the altitude is between $885-2082 \mathrm{~m}$ above sea level, the central and southern is loess plateau gully region, the north and the east are loess hilly-gully region. There are 12 big tableland throughout 6667 hm2 (100000 acres), involving Qingyang, zhengning, heshui, xifeng, it is also the world's largest, soil the thickest, the most intact loess table-land, so can be called "the first loess tableland in the world". Therefore, as an example to study the ecological agriculture development ,longdong loess plateau in Qingyang city has strong representative.

Since the founding of the People's Republic of China, especially since the reform and opening, economic rapid development on the basis of the original Qingyang, speeding up the growth rate of 
economy, the city GDP in 2014, 66.886 billion yuan, 8.062 billion yuan of the added value of agriculture, total grain output of 1.6423 million tons, farmers per capita net income of 5499 yuan. Qingyang contains rich natural resources, among them, 2.847 billion tons of oil reserves make Qingyang changqing oilfield producing, 236 billion tons of coal to make coal reserves accounted for 94\% of total gansu Qingyang; Rich in wheat, corn, oil and other crops and buckwheat, millet, oats and other small grains make Qingyang known as the "longdong granary" of reputation. Rich in natural resources and did not give full play to its comparative advantage, also did not translate into the local economy advantage. The ratio of the three industries of Qingyang city in 2014 was 11.6:59.8:28.6, the ratio of heavy industrial output value as high as 2.4, 97.6, place after the deduction of the state-owned enterprise production industry output value proportion is very small, industrial failed to pull effect on the local economic formation obviously, agriculture in Qingyang still plays a dominant role in the economy.

\section{The Main Mode of Ecological Agriculture Development of Qingyang City}

The characteristic management, the scale operation of industry economy. Based on its characteristics of Qingyang city resources, cultivating the backbone of the agricultural products processing enterprises with good market demand, to the road of scale, specialization, has initially formed to develop characteristic economy industrialization development mode. Among them, the original county town give full play to the consumption of the resource superiority of apricot, by developing a series of special products, has been formed mainly apricot products processing agricultural and sideline products processing industry, not only can make the farmers to increase income of more than 3280 ten thousand yuan a year, and powerful driving the development of the agricultural industrialization; Zhengning using JiuLongChuan distinct seasons, sufficient sunlight natural conditions and convenient highway transportation, built mainly gold jujube, apple fruit, which is mainly composed of greenhouse pollution-free vegetable production bases and characteristics of agricultural science and technology demonstration garden, at the base and demonstration garden, melon and fruit vegetables production accounts for nearly three years the county-wide average is as high as $17.1 \%$ of GDP.

Adjust measures to local conditions, the result of the development of the green economy. To protect the ecological environment, improve the comprehensive agricultural production capacity, Qingyang city have been taken industry development plan of the northern area ,such as huachi ,huan county. There have been Qingyang green xin,Tongda fruit company and other large-scale breeding products processing enterprises, which is annual processing capacity of more than 2500 tons. Under the drive of leading enterprises, the city's production of beef, meat, wool sheep, pig respectively reached 675000, 675000 and 1.141 million, the output of meat, milk and eggs was up to 123000 tons. Of farming and animal husbandry development co., LTD. Investment in gansu industrialization project of broilers, feed processing, poultry slaughter segmentation, meatballs sausage meat and bone meal production to feather processing, sewage treatment, has formed a complete industrial chain, the whole value chain, complete cycle chain in the "model". The development of breeding industry, not only can effectively prevent water loss and soil erosion and sand disasters, inhibition of soil salinization, and can drive the related industries, increase farmers' income.

Low energy efficiency, recycling model of courtyard economy. The model is in accordance with the agricultural ecosystem energy flow and material cycle to form an ecological agriculture pattern. Because our country countryside still with small-scale decentralized family business as the main body, rural households is relatively independent economic unit, so the yard is widely used in the rural economy. Qingyang city garden ecological economy is based on the climate characteristics and the status quo of the resources, guiding farmers to make full use of the house and the yard behind the house of idle land, such as housing, orchards, farmland and grassland resources and other factors of production, by planting flowers, vegetables, medicinal herbs, fruit trees and other economic crops, and raising pigs, cattle, sheep, chickens and other animals, make full use of light, heat, water and soil resources, the rational allocation of biogas, greenhouse, a fruit and library, granary, reduce fuel, feed and fertilizer inputs, multilayer formation energy conversion in the courtyard, efficient utilization of resources, ecological virtuous circle of integrated production 
system.

\section{The Necessity of Ecological Agriculture Development of Qingyang City}

The requirements for improving the efficiency of agricultural production.

1. The agricultural infrastructure is weak, the market system construction lag. Qingyang as a traditional agricultural areas, though in recent years through the development of water-saving rainfed agriculture, agricultural production conditions to change, but there is still a farmland water conservancy facilities dilapidated, irrigation and drainage equipment configuration maintenance problems, such as aging, agricultural machinery facilities lead to weak agricultural production base, the input-output ratio is low, the effective irrigation area of cultivated land is only $9.3 \%$ at present, only equivalent to the national and the province's average of $20.7 \%$ and $20.7 \%$ respectively; Qingyang city of 2014 food crops planting area accounts for $16.2 \%$ of the province's total, but the added value of agriculture only $8.9 \%$ of the total for the entire province; With the deepening reform of economic system, Qingyang is now basically in place including agricultural products trading market, production market, property right trading market, and labor market, rural market system, weak infrastructure, but as a result of market main body organization degree is low, the reason such as the way to trade a single effect, compared with the national and related areas, the main agricultural products in addition to the eggs, meat commercialization degree is slightly higher, the rest of the degree of commercialization of agricultural products is still on the low side.

2. Low level of agricultural industrialization, the leading role of science and technology co., LTD. Scale management is the foundation of the agricultural industrialization, but Qingyang agricultural production cooperation organization and operation of small, short industry chain, economic benefits compared with the national gap is larger, in 2014 the city of ecological-economic GDP per head is differ with the $\mathbf{8 8 3 . 8 4}$ yuan. Science and technology progress is the motive force of agricultural industrialization, but the Qingyang counties agriculture is still mainly adopts the traditional mode of production, in 2014 the city's agricultural fertilizer SheChun amount accounts for only $9.6 \%$ of the province, rural electricity consumption accounted for $11.4 \%$ of the province, agricultural machinery total power only $10.1 \%$ of the province, agricultural production automation, intelligent information-based level is relatively low, such as scientific and technological progress of agricultural industrialization leading role is very limited; Engine is the leading enterprises in agricultural industrialization, Qingyang in recent years the number of leading enterprises engaged in agricultural products processing is increased, but the amount is still less, at present the city's only national and provincial key leading enterprise, 38, and most of the processing technology of traditional enterprise, backward management methods, a single product structure.

3. Lag of the agriculture industry structure, the single leading industry. The Qingyang still predominantly food crops and other economic crops of agricultural structure, to provide industrial raw materials as well as the relatively low proportion of high value-added economic crops, agricultural industrial structure is relatively lag. Although the market economic system has been formed, but due to the inertia influence long-term planning system, various counties in the lack of research on its own resources advantage, market supply and demand situation, adopt executive order way blind, expanding investment, counties all around the fruits, vegetables, breeding, three big industry development, lead to convergence, leading industry resources optimal configuration, partial product sales difficulties, affected the agricultural development and farmers' income.

The urgent request of (2) to improve the regional ecological environment.

1. Improve the needs of the natural ecological carrying capacity. Because of Qingyang counties differences in geographic location and resources endowment, the ecological security situation is not balanced, the heshui, huachi, zhengning county, and zhengning county is located in the radial end, dense forest in the area, the vegetation is good, is a major timber production base of Qingyang, ecological status overall better than the other counties; The original county town, county, town deqing county, xifeng district and the surrounding area of forest area, returning farmland to forest in the mountains slope artificial afforestation survival rate, survival rate is low, the lack of vegetation and illegal mining, grazing, plant diseases and insect pests, such as reason, wind erosion and desertification, climate anomalies and other ecological problems worse. Zhang Zhi congruent (2010) on the dynamics of the ecological footprint and ecological capacity of Qingyang city the research 
results show that the per capita ecological footprint of Qingyang city increased year by year, the per capita ecological carrying capacity is reducing year by year, the ecological carrying capacity supply (ecological footprint) and ecological carrying capacity demand showed a trend of changes in the opposite direction; Research also suggests that the more the economy developed area, the greater the demand for ecological footprint, the ecological footprint of Qingyang will be improved with the development of regional economy further, this will inevitably lead to ecological degradation. Qingyang is the inheritance of the farming culture, to maintain the natural ecological balance, the need to develop ecological agriculture.

2. Ease the plight of regional soil and water loss. Soil erosion of the loess plateau has been a significant ecological problem, it is also one of the main factors which restrict the development of the Qingyang agricultural economy. Water network density index is used to reflect the evaluation of regional water resources abundant lean degree, the evaluation results showed that water network of Qingyang city density index is 3.63, surface runoff is only $0.038 \mathrm{~km} / \mathrm{km} 2$, and geographical position close, is rich in water resource in southern shaanxi is $1.46 \mathrm{~km} / \mathrm{km} 2$. Because networks, sparse, shortage of water resources of Qingyang city ", per capita water resources, $305 \mathrm{~m} 3$, only $13 \%$ of the national average; Cultivated land per acre possession of $72 \mathrm{~m} 3$ of water, only $10.8 \%$ of the national average, networks, sparse restricted the Qingyang economic industry layout, the shortage of water resources also limits the Qingyang agricultural development. Land degradation index is used to reflect the evaluation of regional land degradation degree. Because is located in the loess plateau, soil erosion, desertification, Qingyang is one of serious mountain disasters area in our country, the land degradation index is 40.27 , the ecological environment is the state of weakness. Although Qingyang municipal government in recent years, the geological disasters such as landslide, debris flow, mountain torrents prevention into special funds, completed the tens of thousands of square kilometers of soil and water conservation comprehensive treatment, but because of the steep terrain, heavy rainfall concentration factors such as time restriction, the prevention and control of soil erosion is still a long way to go.

3. The implementation of carbon balance in the area of need. Area of resource consumption and environmental pollution condition, usually closely related to its economic structure. Rich in oil resources to drive Qingyang three show obvious "132" type of industry structure. Petrochemical industry is the energy consumption and greenhouse gas emitters, most of the oil field has entered the middle and later periods of the development, Qingyang ground construction scale expands unceasingly, energy-intensive production ratio increases, the exploration and development in the field of energy-saving pressure; Longdong region due to expand production scale and the quality of crude oil is heavy, inferior, the market product quality requirements are constantly improve, the CO2 emissions intensity in the field of oil refining and chemical industry is therefore difficult to cut; Oil and gas storage and transportation links in greenhouse gas emissions are mainly concentrated in the pipeline, oil heating, a large number of mining will inevitably increase the field of natural gas energy of greenhouse gas emissions. To control carbon emissions, increase the amount of carbon sink, realize regional carbon balance, oil field enterprises should act, Qingyang traditional management should also be ecological agriculture industry.

\section{Path selection of ecological agriculture development of Qingyang city}

Countries experience for reference for the development of ecological agriculture.

1. Japanese experience of perfecting legal system, attaches great importance to the development of science and technology. Japan is an island, land area accounts for only $0.27 \%$ of the world's land area, arable land, less than $14 \%$, the per capita arable land area of less than $0.07 \mathrm{hm} 2$, relatively poor in natural resources. After world war ii, Japan successively promulgated the "forest law", "agricultural land law", the act of poultry excretion, "sustainable farming" and a series of law and provides legal protection for ecological agriculture development; Japan not only attaches great importance to the ecological agriculture science and technology investment and development, and accelerate the development of ecological agriculture based on modern science and technology and application, the implementation of the organic agricultural standards (JAS) certification, special cultivation of agricultural products, ecological agricultural products certification for such certification system of agricultural production and consumption, scientific research, production, 
processing and consumption effectively, has become one of the ecological agriculture development good countries around the world.

2. The Israel experience of water-saving agriculture development. Israel lies between the Sahara desert and gobi desert, more than half belongs to the arid and semiarid area of land, few Mediterranean coast and inland river valley near can find some land farming. To improve agricultural production environment, the middle of the 20th century, Israel pioneered trace represented by drip irrigation technology, with a specific standard, at a certain time will be needed to make plants grow moisture and nutrient, use pipeline passed directly to the plant roots and ensure that the $80 \%$ - $80 \%$ of the effective use of water, maximum limit access to the land and the economic benefits of unilateral water unit. Micro irrigation technology is widely applied in the country's crop production, as well as trees, grass and flowers planted, also effectively improved the saline-alkali land, than in the early $1940 \mathrm{~s}$, the land of Israel extend 2.6 times, the effective irrigation area is increased by 7.5 times, can support population increased by 12.4 times; Its agricultural products in addition to self-sufficiency, still can achieve more than $\$ 1.3$ billion in export revenues each year, created the miracle of the world agriculture development.

3. The Switzerland experience of agricultural vocational education. In order to change the agricultural proportion in national economy, the lower the traditional situation, after the $1990 \mathrm{~s}$, the Swiss government and increase support for advantage agricultural industry emphasis on environmental protection and improve the agricultural self-sufficiency as the necessary premise of agricultural development, most countries implement the incomparable agricultural vocational education, not only on the function of education have a clear division of labor, and established a special research department to study its development; Not only the establishment of a complete, advanced teaching place of agricultural facilities, and in the education of cultivating students' practical operation ability; Practical technology institute of the country, not only requires cadets enrolled must have experience in agriculture, and graduate to get the corresponding certificate of technical qualifications. At present, the Swiss agricultural products in international markets for agricultural products export share a larger proportion, its organic food is exported to all over the world.

The specific way of ecological agriculture development of Qingyang city.

1. Understand ecological agriculture, establish and improve the security system. Qingyang a fragile ecological environment seriously restricts the sustainable development of local economy, the development of ecological agriculture is imminent. In order to ensure the ecological agriculture development, need from Qingyang agricultural science and technology strength, according to the present conditions of agricultural resources, create a common standard, let the ecological agricultural management on a path to legalization. To establish suitable for local ecological agriculture development policy and legal security system, and ensure the maneuverability of the law, policy; 2 to standardize the ecological agriculture to manage department, each department responsibilities, play to the functions of each department; Third, according to the market situation and timely adjust prices for agricultural products and agricultural subsidies standards, protect the lawful rights and interests of farmers; Fourth, we need to strictly in accordance with the "green food" formulated by the state, "pollution-free agricultural products" and "organic food" standard, to carry out the specific implementation details, such as declaration, attestation to enhance the level of quality and safety of agricultural products.

2. Optimize the agricultural industrial structure; promote the industrialization of agriculture. With the transformation of people food consumption structure, high nutrition, high-energy food consumption increased significantly, this would require the adjustment of agricultural industrial structure, development is given priority to with farming and forestry of the local industry, according to the regional characteristics of counties choose suitable industry direction. In county with poor natural conditions, implement mountain gully grazing prohibition, planting grass and raising sheep and build the base of animal husbandry; Good xifeng district, the condition of agricultural production can planting is given priority to aquaculture development of agriculture; In meridional ridge foothills heshui, should make full use of its abundant hot water resources, forestry resources and good environment, planting black fungus, dangshen and other Chinese medicinal materials and economic crops, such as walnut, pepper, establishing production base of per product, expand the 
grassland, forest land and water area. At the same time, also to encourage peasants to set up all kinds of rural professional cooperative organizations, cultivate and strengthen leading enterprises, increasing scientific and technological innovation, extend industry chain, to enhance the level of industrialization boost ecological agriculture development.

3. Rationally utilize the cultivated land resource, realize ecological agricultural scale management. Qingyang effective cultivated land resource is very limited, with the speeding up of urbanization, the construction, industrial and mining land continue to increase, basic farmland cultivated land red line faces severe challenges. Therefore, local government should strictly implement the system of land use, management, increase the intensity of compensation regulation of cultivated land, the maximum guarantee agricultural cultivated land; Should be appropriate to ground the industrial factory building, urban construction, aquaculture projects such as difficult to vegetation restoration, severe degradation of barren hills, slope, save the ground, gentle slope for soil and water conditions to demand higher planting industry development; Do a good job in land made by archivist files strengthen the right to the contracted management of land circulation, safeguard ecological agricultural scale management of land. At the same time, also should strengthen the farm machinery, water conservancy, transportation and other infrastructure construction and maintenance, standardize the market for agricultural products and agricultural means of production, increase the intensity of meteorology, agricultural information platform construction, build good foundation for the development of ecological agriculture.

4. Manage the agricultural ecological environment; improve farmers' living conditions. First of all, to actively promote crop straw returned, physics and insects pests and biological control technology, increasing organic fertilizer application, reduce the use amount of chemical fertilizers and pesticides, control of land pollution, improve soil structure, strengthen land continual production ability. Next, want to change the extensive mode of production water, promotion of sprinkler irrigation and micro-irrigation, drip irrigation and other water-saving irrigation technology, to realize the effective utilization of water resources, and increase the grassland, such as strengthening the construction of basic farmland measures of small watershed comprehensive treatment, and realize the sustainable utilization of water resources. Again, to encourage farmers to the large slope, low yield farmland returning farmland to forest (grass), the development of animal husbandry and high value-added economic crops, and accelerate the construction of forest carbon sink forest, ecological landscape, the implementation of afforestation YuCao, is strictly prohibited to overuse of barren hill slope, grazing and other predatory management, restore vegetation, inhibition of soil and water loss. At the same time, to improve the rural traditional way of life, relying on the biogas project, rational utilization of animal waste residues, agricultural products, scientific processing travel-weary mulch, agricultural materials packaging, such as agricultural waste, clear in time farmers living garbage and sewage, regulation of rural environmental pollution, and combining the village layout adjustment, central village construction, former renovation, land consolidation and rural infrastructure construction, carry out the rural environment protection and ecological construction.

5. Develop vocational technical education; deeply popularize agricultural science and technology. Conditioned by geographical location and traffic conditions, in Qingyang, the farmers ideology is universal conservative, and deeply small-scale peasant consciousness, the rural labor transfer deposit leads to low quality of laborers in the country, and the education of the rural population is shorter, so more farmers' attitude to agricultural new technology and new product shows negative wait-and-see, has affected the use in the promotion of agricultural science and technology achievements. Therefore, it is necessary to ecological agriculture knowledge and skills training for the farmers by a variety of ways. First of all, to give full play to the basic function of education in local colleges, in the development planning, professional Settings, training target, etc, in harmony with the local economic development needs, the school to jointly build an open system of vocational education and training; Next, want to rely on local institutions such as vocational colleges, technical schools, vocational high school, taking training before they charge, by civilian and government to pay the training form, promoting agricultural skills training; Again, to build a flexible timely training mechanisms, courses, according to the needs of farmers to take the field guide, the discussion, special reports, and other practical agricultural technology to promote the 
form, improve the quality of farmer science and technology culture.

\section{References}

[1] Chang-bin Yin, Leilei Cheng etc. Type ecological civilization path choice of agricultural sustainable development [J]. Journal of Chinese agricultural resources and gegional, 20154 (2) : 16-21.

[2] Zhang Zhiquan ai-zhong yu, zhu-zhu luo, etc. Dynamic study of Qingyang city, gansu province, the ecological footprint and ecological capacity [J]. Journal of grass industry, 2010, 12 (4) : 187-193.

[3] Lin He,Guangzhong Cao. New century economy sustainable development strategy research of Qingyang city [J]. Chinese desert, 2004, 24 (1) : 51 and 55. Yuan-hong zheng et al.

[4] Dongling Mou, guizhou bijie pilot area ecological agriculture development thinking [J]. Journal of guizhou agricultural sciences, lancet, 2015 (9) : 256-258.

[5] Qingyang City Bureau of Statistics.Qingyang statistical yearbook [M]. China statistical publishing house, 2012-2015.

[6] H/JT192-2006, the ecological environment evaluation of technical specifications (trial) [S].

[7] Shisheng Zhou.Japan the development of ecological agriculture and its enlightenment to the western region of China [J]. Journal of world agriculture, 2015433 (5) : 151-153.

[8] Xibin Song.Israeli water-saving agriculture development of ecological agriculture in China enlightenment [J]. Journal of world agriculture, 2014421 (5) : 56-58.

[9] Yuande Zhi.Swiss ecological agriculture development and research [J]. Journal of world agriculture, 2014422 (6) : 174-176. 